\title{
Reconstructing the Western North Pacific Summer Monsoon since the Late Nineteenth Century
}

\author{
Inmaculada Vega, David Gallego, Pedro Ribera, and F. De Paula Gómez-Delgado \\ Departamento de Sistemas Físicos, Químicos y Naturales, Universidad Pablo de Olavide, Sevilla, Spain
}

\section{RICARDO GARCÍA-HERRERA}

Departamento de Física de la Tierra II, Facultad de Ciencias Físicas, Universidad Complutense de Madrid, and Instituto de Geociencias, Centro Mixto del Consejo Superior de Investigaciones Científicas-Universidad Complutense de Madrid, Madrid, Spain

\section{CRISTINA PEÑA-ORTIZ}

Departamento de Sistemas Físicos, Químicos y Naturales, Universidad Pablo de Olavide, Sevilla, Spain

(Manuscript received 25 May 2017, in final form 27 September 2017)

\begin{abstract}
A new index, the western North Pacific directional index (WNPDI), based on historical wind direction observations taken aboard sailing ships, has been developed to characterize the western North Pacific summer monsoon (WNPSM) since 1898. The WNPDI measures the persistence of the surface westerly winds in the region $5^{\circ}-15^{\circ} \mathrm{N}, 100^{\circ}-130^{\circ} \mathrm{E}$ and easterly winds in the region $20^{\circ}-30^{\circ} \mathrm{N}, 110^{\circ}-140^{\circ} \mathrm{E}$, exhibiting a consistent relationship with the summer precipitation in the areas affected by the WNPSM throughout the entire twentieth century. Its length doubles that of the previous WNPSM index (1948-2014) based on reanalysis products, which allows uncovering different relevant features of the WNPSM variability. The WNPSM had a significant interdecadal variability throughout the twentieth century. In particular, the period 1918-48 was characterized by less variable and stronger monsoons than in recent decades. Additionally, the relationship between the WNPSM and ENSO or El Niño Modoki has been evaluated during the entire twentieth century for the first time. It is confirmed that the WNPSM tends to be strong (weak) when El Niño (La Niña) develops during the whole record. Nevertheless, the relationship during the ENSO-decaying phase is not stable in time. Thus, the WNPSM tended to be strong (weak) when La Niña (El Niño) decayed only since the late 1950s, with an opposite relationship in the earliest part of the record. El Niño Modoki shows a rather stable and high correlation with the WNPDI during the whole study period throughout the twentieth century.
\end{abstract}

\section{Introduction}

The Asian-Pacific monsoon is one of the most energetic components of the climate system, and it has been traditionally subdivided into three different components: the Indian summer monsoon (ISM), the East Asian summer monsoon (EASM), and the western North Pacific summer monsoon (WNPSM) (Wang and LinHo 2002), the latter being first introduced as an independent structure by Tao and Chen (1987). The WNPSM shows a pronounced year-to-year variability and triggers profound impacts on the global climate (e.g., Wang et al. 2001; Lee et al. 2014; Choi et al. 2016;

Corresponding author: Inmaculada Vega, ivegmar@upo.es
Zhang and Luo 2016), impacting on highly populated areas significantly (Wang et al. 2001). Nevertheless, this monsoon has received little attention in comparison to the EASM and the ISM, possibly due to the scarcity of observations since its core is usually considered to be located in the domain $10^{\circ}-20^{\circ} \mathrm{N}, 110^{\circ}-160^{\circ} \mathrm{E}$ (Murakami and Matsumoto 1994).

In the last two decades, a number of studies have been published aiming to identify the mechanisms responsible for the variability of the WNPSM, which could be affected by phenomena that take place in the Indo-Pacific region. Some studies compare the different components of the Asian-Pacific monsoon system; for instance, the WNPSM is usually out of phase with the EASM (e.g., Wang et al. 2001), although this relationship shows decadal changes 
(Kwon et al. 2005; Yim et al. 2008). Wang and Fan (1999) pointed out that, despite sharing some features, the ISM and the WNPSM should be considered separately because the convection sources that drive them, located in the Bay of Bengal and near the Philippines, respectively, are poorly connected. Additionally, the variability of the Asian monsoon system seems to have been mostly related to that of the WNPSM rather than the ISM or the EASM in recent decades (Lee et al. 2014).

Another part of the literature dealing with the WNPSM is focused on its relationship with global climate modes such as El Niño-Southern Oscillation (ENSO) or El Niño Modoki, which seems quite complex. For instance, Tanaka (1997) noted that the onset dates of the WNPSM were modulated by the phase of the ENSO throughout the period 1978-92, when the Niño-3 index stopped being biennial. Moreover, the monsoon was often strong during La Niña years (Tanaka 1997). Later, Chou et al. (2003) showed that the ENSO-WNPSM coupling depends more on the ENSOdeveloping stage than on its sign. A strong (weak) WNPSM tends to occur within El Niño (La Niña)developing year and/or La Niña (El Niño)-decaying year. On the other hand, several studies (Weng et al. 2007, 2011; Lee et al. 2014) pointed out that the WNPSM tends to be stronger in the course of El Niño Modoki events. Nevertheless, oscillations with different periodicities, such as the Indian Ocean dipole (IOD; Saji et al. 1999), might co-occur with El Niño or El Niño Modoki influencing each other (e.g., Weng et al. 2011; Wang and Wang 2014; Zhang et al. 2015). For instance, Feng and Chen (2014) remarked that a positive phase of the IOD weakens the relationship between the WNPSM and El Niño Modoki. Thus, characterizing the climatic impact of a tropical mode of variability while others occur simultaneously is not easy because of the nonlinearity of these interactions (Weng et al. 2011). Therefore, unveiling the relation of the WNPSM with global climate still constitutes a research challenge.

All these analyses are based on the study of a relatively short history of the WNPSM limited to the second half of the twentieth century, which constitutes an additional difficulty. To improve the present knowledge of this monsoon and its relation with the global climate, it would be necessary to extend the currently available series of the monsoon's strength back in time. Since the WNPSM is largely oceanic, there is a lack of in situ observational data or even satellite-derived data prior to the 1970s. The strength of monsoons is often quantified either by precipitation-based indices or by dynamical indices through the analysis of the wind field. Usually, the longest monsoon series are those based on precipitation, a variable that captures most of the changes in the monsoonal circulation (Wang and LinHo 2002) and is available since the early twentieth century in some areas. For instance, the all-Indian rainfall index (Parthasarathy et al. 1994), based on long precipitation series over India, has been extensively used to characterize the ISM since the beginning of the twentieth century. Unfortunately, the absence of sufficient land areas in the WNPSM domain hampers the development of similar indices for this monsoon. Furthermore, recently it has been suggested that in changing climates a decoupling between monsoon-related precipitation and monsoonal circulation strength is possible (Fan et al. 2009). Consequently, indices based on dynamical variables are currently preferred to quantify the long-term monsoonal variability (Fan et al. 2009).

The structure of the summer monsoonal wind pattern in the western North Pacific (WNP) is characterized by a southwesterly flux over the Philippines, related to the eastern branch of the Somali jet, which converges with the easterlies from the North Pacific subtropical high over eastern China. This dipole-like wind pattern has been the basis for the dynamical indices defined to quantify the WNPSM (Wang and Fan 1999). Nowadays, the best representation of the strength of the WNPSM is the so-called western North Pacific monsoon index (WNPMI), defined as the difference of the average zonal wind at $850 \mathrm{hPa}$ inside the areas $5^{\circ}-15^{\circ} \mathrm{N}, 100^{\circ}-$ $130^{\circ} \mathrm{E}$ and $20^{\circ}-30^{\circ} \mathrm{N}, 110^{\circ}-140^{\circ} \mathrm{E}$ (denoted as D1 and D2, respectively; see Fig. 1) by Wang et al. (2001). High WNPMI values reflect enhanced westerlies at D1 and enhanced easterlies at D2 and consequently a strong monsoon. This index is based on the NCEP-NCAR reanalysis data starting in 1948, and there have been no attempts to extend it backward in time, possibly due to the relative absence of in situ wind measurements over the Pacific Ocean prior to the 1950s.

In this regard, the earliest measurements of wind over oceanic surface were taken aboard ships. As wind was the most important variable from the point of view of navigation, it was routinely measured and preserved in logbooks, offering the best potential to develop longterm climate indices (García-Herrera et al. 2005). As a result of several international recovery projects, most of those data are available in digital form in the International Comprehensive Ocean-Atmosphere Data Set (ICOADS), which nowadays stands as the most complete source of observed surface marine data spanning the past three-and-one-half centuries. The concept of indices based on historical wind measurements was suggested by Wheeler et al. (2010), who used the wind direction field to obtain the first truly instrumental reconstruction of the wind circulation over the English Channel from 1685 to 1750 . Barriopedro et al. (2014) 
(a) Number of JJA wind direction observations

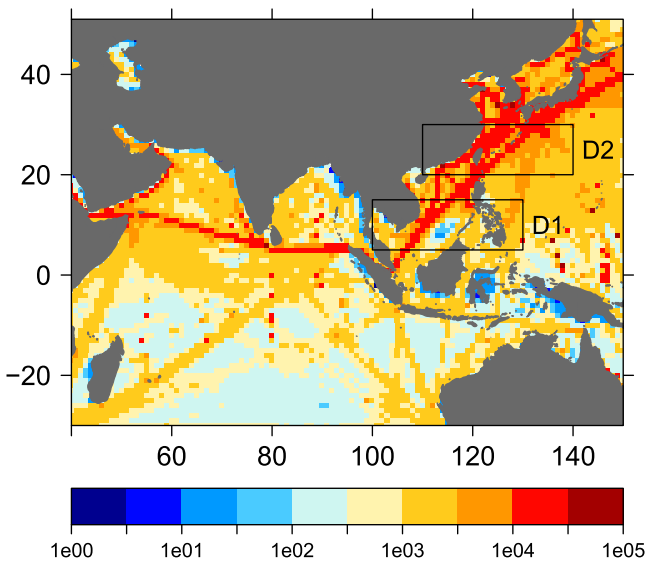

(b) D2: [110-140E; 20-30N]

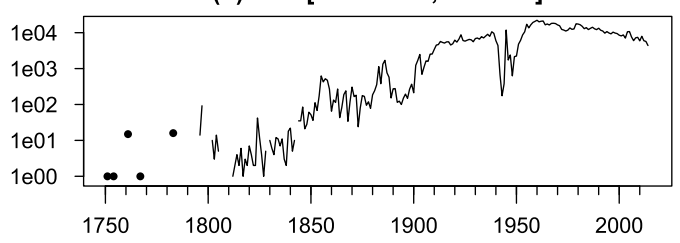

(c) D1: [100-130E; 5-15N]

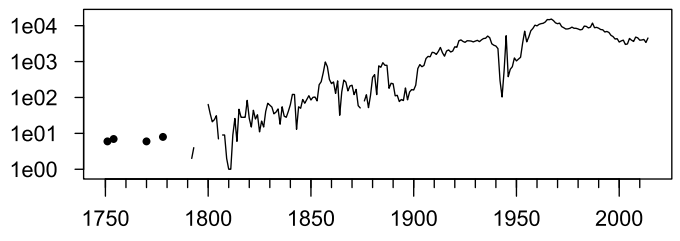

FIG. 1. (a) Gridded observations in ICOADS for summer (JJA) throughout the period 1750-2014. Evolution of the number of observations inside the regions (b) D2 and (c) D1 for the same period.

generalized the so-called directional indices being applied to the quantification of the North Atlantic atmospheric circulation since 1685. Gallego et al. (2015) extended this technique to the study of monsoonal circulations and developed an index measuring the strength of the West African monsoon back to 1840 . Recently, Ordóñez et al. (2016) used a similar approach to estimate the date of the ISM onset, proving that in some cases, directional indices are sensitive enough to catch fine-detail characteristics of a monsoon as the onset date.

The main aim of this paper is to analyze the variability of the WNPSM since the late nineteenth century by developing a new index based on in situ historical wind direction observations taken on board ships. The data and methods employed in this study are described in section 2 . The temporal structure and the variability of the new index are presented in section 3. Section 4 provides an analysis of the long-term variability throughout the twentieth century and the relationship between the WNPSM and the ENSO, El Niño Modoki, and the IOD. Finally, the main conclusions are given in section 5 .

\section{Data and methodology}

Historical wind data usually contain information about force and direction; however, wind force taken aboard ships required some degree of subjective judgement prior to the midtwentieth century, so it cannot be regarded as a fully instrumental measurement. Despite this fact, the wind force contained in logbooks has been successfully used to develop synoptic-scale climate reconstructions in multiproxy approaches (Küttel et al. 2010). Nevertheless, the methodology used to translate the qualitative wind force terms into quantitative data might limit the development of climatic indices (Prieto et al. 2005). For instance, Gallego et al. (2007) showed that while the seasonal cycle of the wind force in a location is usually accurately reproduced by historical observations, this is not necessarily the case for the absolute magnitude of the wind. Depending on the ship's country and the epoch, a climatology based on converted wind force observations can overestimate the wind speed in a location by a factor of up to 2 times the present-day climatological value. As this bias is space and time dependent, it should be translated as uncertainty in any index relying on historical wind force estimations. This is not the case of the wind direction. This variable was measured using a compass essentially in the same way as it is done nowadays, and, therefore, it does not need a conversion to numerical values nor rescaling beyond the correction necessary to refer the magnetic to the geographic north. This fact remains true even for the earliest observations. In this way, wind direction measurements can be regarded as instrumental. This feature has been recently exploited to develop instrumental climate indices capable of going back in time as early as the seventeenth century (Wheeler et al. 2010; Barriopedro et al. 2014; Gallego et al. 2015; Ordóñez et al. 2016; Mellado-Cano et al. 2017, manuscript submitted to J. Climate).

Our source of wind direction data has been ICOADS, which starts in 1662 and contains over 455 million individual marine reports in its most recent release (release 3.0; ICOADS 3.0). This database is essentially composed of historical observations and metadata reported from ships and retrieved from logbooks up to the first third of the twentieth century and data from buoys, coastal platforms, and oceanographic instruments ever since (Freeman et al. 2017). 
Following the methodology developed by Barriopedro et al. (2014) and Gallego et al. (2015), we adapted the definition of the WNPMI (Wang et al. 2001) to the use of wind direction alone but substituting the changes in the zonal wind for changes in the frequency of days with prevalent wind blowing from the west at D1 or the east at D2. Our new western North Pacific directional index (WNPDI) is then defined as the sum of the percentage of days in a month with prevailing wind blowing from the west (wind direction between $225^{\circ}$ and $315^{\circ}$ from the true north) at D1 and the percentage of days in a month with prevailing wind blowing from the east (wind direction between $45^{\circ}$ and $135^{\circ}$ from the true north) at D2:

$$
\begin{aligned}
\text { WNPDI }= & {\left[\frac{\text { No. of westerly days }}{\text { No. of days with observations }}(\mathrm{D} 1)\right.} \\
& \left.+\frac{\text { No. of easterly days }}{\text { No. of days with observations }}(\mathrm{D} 2)\right] \times 100 .
\end{aligned}
$$

As the WNPDI is constructed from the percentage of days with wind blowing from the west or the east, it is necessary to define a westerly (easterly) wind day at each region. In this sense, when only one daily observation is available inside the region D1 (D2), the day is classified from the wind direction of that single observation. If several observations per day are available, which is the most typical case, the day is considered as a "westerly (easterly) wind day" when a minimum percentage $P$ of the total number of observations available for that day corresponded to westerly (easterly) winds. The values of $P$ were chosen as those maximizing the correlation between our directional index and the WNPMI of Wang et al. (2001) for the concurrent period (1948-2014), resulting in $P=39 \%$ at D1 and $P=46 \%$ at $\mathrm{D} 2$. With these values, the correlation between the new WNPDI and the WNPMI reaches $+0.87(p<0.01)$, indicating that although the WNPDI does not include information about wind force, it captures a large part of the variance associated with the monsoon. Seasonal values of the WNPDI are computed as the June-August average.

As demonstrated by Gallego et al. (2015) a number of around 100 wind direction observations per season inside an area is needed to obtain a good representation of a directional index. Figure 1a shows the cumulative number of wind direction observations in the ICOADS 3.0 database aggregated in a $1^{\circ} \times 1^{\circ}$ grid between 1750 and 2014 for the boreal summer. Some of the busiest commercial historical routes in the world ran from the Indian Ocean into the South China Sea to Japan and the Pacific Ocean (see Fig. 1a), and as a consequence, a large number of wind observations over both domains are available. Figures $1 \mathrm{~b}$ and $1 \mathrm{c}$ show the temporal evolution of the number of observations inside the regions $\mathrm{D} 2$ and $\mathrm{D} 1$, respectively. By the second half of the nineteenth century the required 100 wind observations per season are relatively frequently found, even reaching more than 500 observations per season some years. However, it is at the beginning of the twentieth century when a dramatic increase in data availability in both domains is observed, and since 1910 the number of observations per summer is usually higher than 2000 , offering very good coverage, except for the World War II period. A total of 1667968 individual wind direction observations in both D1 and D2 were used to compute the WNPDI.

Additionally, we have employed the wind field at $10 \mathrm{~m}$ from the NOAA Twentieth Century Reanalysis (20CR, version v2c; Compo et al. 2011) and the European Centre for Medium-Range Weather Forecasts (ECMWF) twentieth-century reanalysis (ERA20C; Poli et al. 2016) in order to compute directional indices of the WNPSM and compare them with our WNPDI based on the ICOADS. To evaluate precipitation changes, monthly precipitation data on land surface at a $0.5^{\circ} \times 0.5^{\circ}$ resolution grid have been derived from the Global Precipitation Climatology Centre version 7 (GPCCv7; Schneider et al. 2014) database. Vertically integrated moisture transport associated with the WNPSM has been evaluated following Trenberth and Guillemot (1995) by using the specific humidity and zonal and meridional wind between 1000 and $300 \mathrm{hPa}$ from the NCEP-NCAR Reanalysis-1 (Kalnay et al. 1996).

To analyze the relationship between the WNPDI and ENSO, El Niño Modoki, or IOD, we have computed the corresponding indices by using the monthly $1^{\circ} \times 1^{\circ}$ gridded SST data from the Centennial In Situ Observation-Based Estimates of SST (COBE-SST) dataset (Hirahara et al. 2014) provided by the NOAA/ OAR/ESRL Physical Sciences Division (PSD), previously detrended at each grid point. In this study, we quantify ENSO by both the Niño-3 (EN3) and Niño-3.4 (EN3.4) indices, defined as the SSTA averaged over the regions $5^{\circ} \mathrm{S}-5^{\circ} \mathrm{N}, 210^{\circ}-270^{\circ} \mathrm{E}$ and $5^{\circ} \mathrm{S}-$ $5^{\circ} \mathrm{N}, 190^{\circ}-240^{\circ} \mathrm{E}$, respectively. El Niño Modoki index (EMI) is defined following Ashok et al. (2007) as $\mathrm{EMI}=\mathrm{SSTA}_{\mathrm{C}}-0.5\left(\mathrm{SSTA}_{\mathrm{E}}\right)-0.5\left(\mathrm{SSTA}_{\mathrm{W}}\right)$, where subscripts $\mathrm{C}, \mathrm{E}$ and $\mathrm{W}$ correspond, respectively, to the regions $10^{\circ} \mathrm{S}-10^{\circ} \mathrm{N}, 165^{\circ}-220^{\circ} \mathrm{E} ; 15^{\circ} \mathrm{S}-5^{\circ} \mathrm{N}, 250^{\circ}-290^{\circ} \mathrm{E}$; and $10^{\circ} \mathrm{S}-20^{\circ} \mathrm{N}, 125^{\circ}-145^{\circ} \mathrm{E}$ where the SSTA were averaged over. The IOD is quantified by the Indian Ocean dipole mode index (DMI; Saji et al. 1999), 


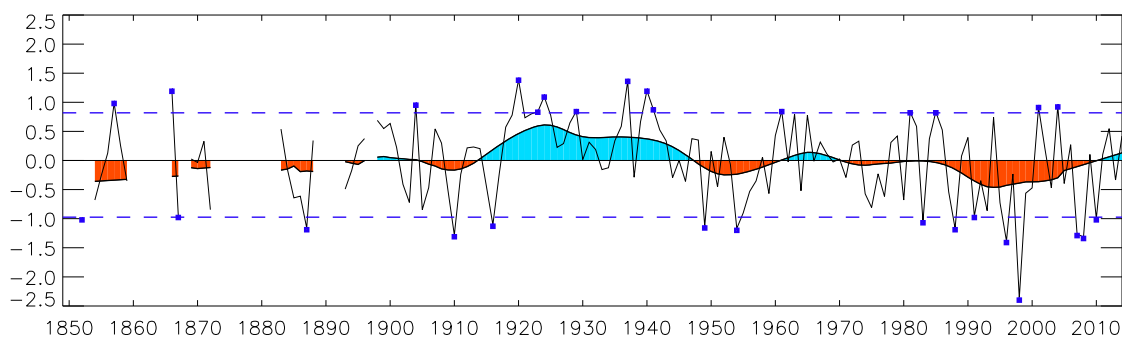

FIG. 2. Evolution of the standardized JJA WNPDI (thin black line), robust locally weighted regression with a 21-yr window (shaded curve), and extreme monsoons (blue-filled squares) based on the 10th and 90th percentiles (dashed blue lines) of the WNPDI for the period 18492014.

computed as the difference of the SSTA averaged over the regions $10^{\circ} \mathrm{S}-10^{\circ} \mathrm{N}, 50^{\circ}-70^{\circ} \mathrm{E}$ and $10^{\circ} \mathrm{S}-0^{\circ}, 90^{\circ}-$ $110^{\circ} \mathrm{E}$.

\section{The western North Pacific directional index}

With the current ICOADS 3.0 data coverage it has been possible to compute the summer WNPDI for several years starting in 1849 and in a continuous form since 1898 , thus doubling the length of the previously available index for the WNPSM. Figure 2 shows the WNPDI series, which has been standardized with respect to the period 1900-2010. Similarly to the WNPMI, high (low) values of the WNPDI are associated with strong (weak) monsoons. In this regard, the new index series shows a tendency of the WNPSM to remain in strong/weak phases for long periods in the twentieth century. In particular, the period 1918-48 exhibits predominant positive values of the WNPDI, indicating that those years were characterized by persistent strong monsoons. On the other hand, despite the high interannual variability of the series, it shows predominance of negative values and, in consequence, a tendency to weaker monsoons between 1983 and 2013. These two periods result in a moderate but significant $(p<0.01)$ negative trend of 0.52 standard deviations per century for the WNPDI during the twentieth century.
Figure 3 shows the comparison of our new WNPDI based on the ICOADS with analogous indices derived from the 20CR and the ERA-20C data. The three indices are essentially equivalent since the 1950s, but they mostly disagree during the first half of the twentieth century. The Pearson correlation coefficients between ICOADS and 20CR (ERA-20C) indices are 0.36 with $p<0.01(0.23 ; p<0.10)$ for the period $1900-55$ and 0.78 with $p<0.01(0.91 ; p<0.01)$ for the period 1956-2010. It is remarkable that even the two indices based on reanalysis are quite different from each other [the correlation coefficient between both indices varies from 0.48 $(p<0.01)$ in the period $1900-55$ to $0.78(p<0.01)$ in the period 1956-2010]. To test the consistency of each index against independent observational data, we analyzed the correlation of the three WNPDI with the GPCCv7 monthly precipitation for the periods 1901-50 and 1951-2010 (Fig. 4). The correlation maps for the latter period (Figs. 4d-f) are essentially equivalent for the three indices, showing negative correlations in the Yangtze and Huai River valleys, southeastern India, Malaysia, Sumatra, Borneo, and part of Japan, whereas positive correlations are found in the northern Philippines, the west coast of Myanmar, and eastern Indochina. Nevertheless, only the WNPDI based on ICOADS shows a similar precipitation signal in the period 1901-50 (Fig. 4a). The correlations with the indices based on reanalyzed winds are lower and not

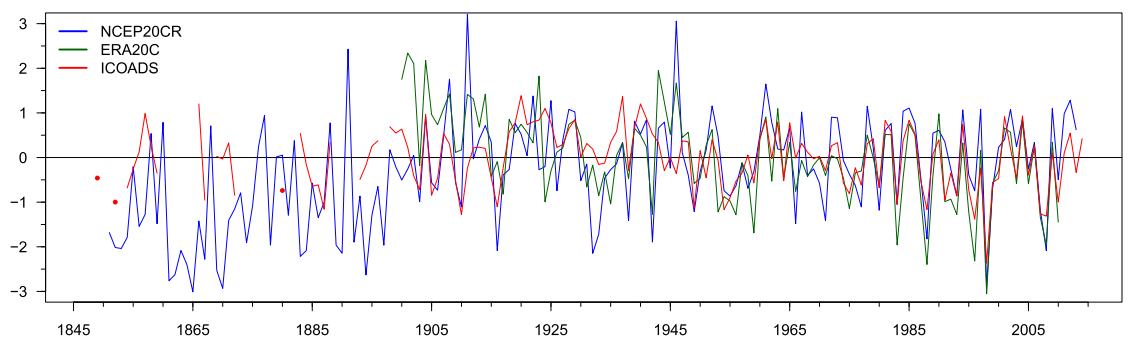

FIG. 3. Evolution of the standardized JJA WNPSM indices based on ICOADS (red), 20CR (blue), and ERA-20C (green) data. 
(a) ICOADS 1901-1950

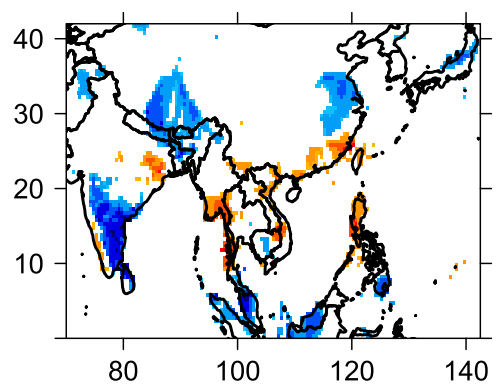

(d) ICOADS 1951-2010

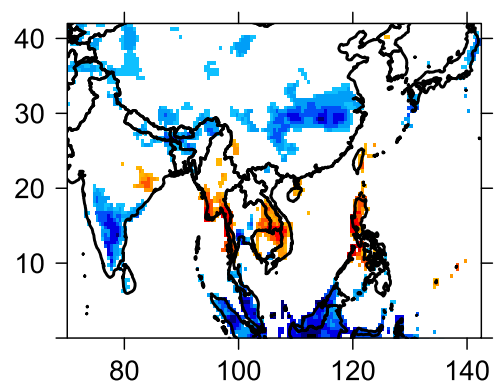

(b) 20CR 1901-1950

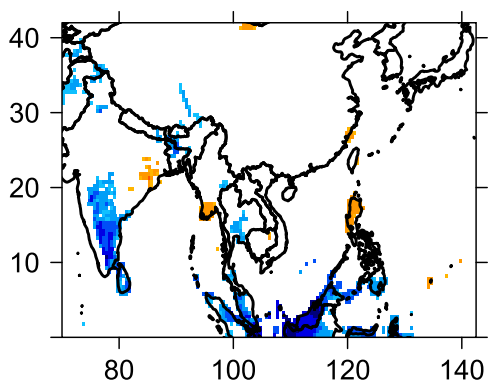

(e) 20CR 1951-2010

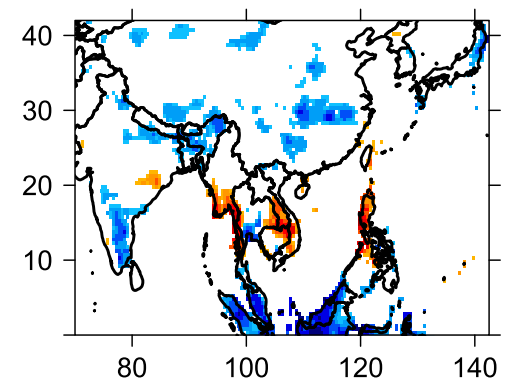

(c) ERA20C 1901-1950

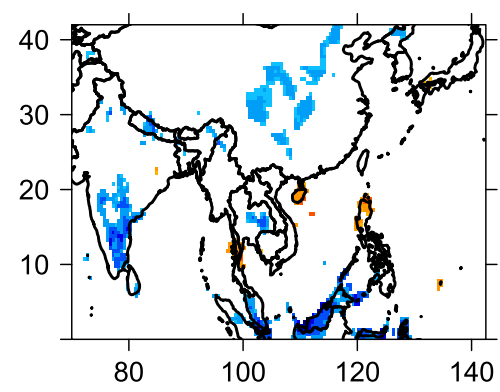

(f) ERA20C 1951-2010

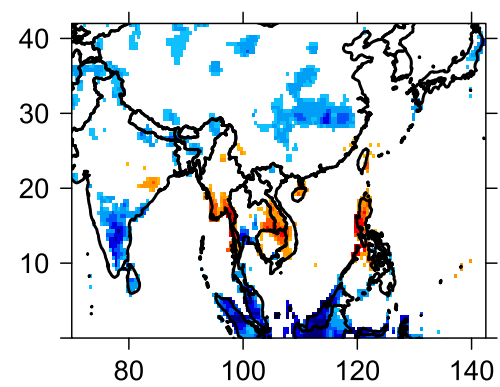

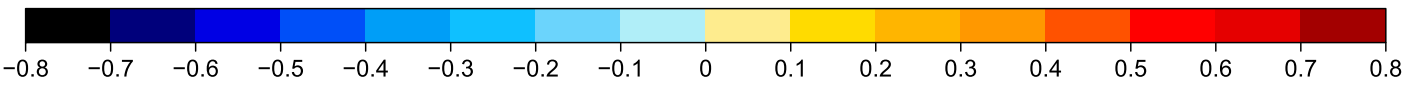

FIG. 4. Correlation maps between the WNPSM indices based on (a),(d) ICOADS, (b),(e) 20CR, and (c),(f) ERA-20C data and summer (JJA) precipitation during the periods (top) 1901-50 and the (bottom) 1951-2010. Shading denotes what is significant at the 95\% confidence level.

statistically significant for many of the previously cited areas (Figs. 4b,c). Despite its relevance, this important result must be taken cautiously because the number of stations included in the GPCCv7 database during the interval 1901-50 is significantly lower than for the latter period and some regions in Indonesia can suffer from low precipitation data coverage (Schneider et al. 2014). Nevertheless, despite this limitation, this result strongly suggests that the index based on the ICOADS represents the monsoon signature on precipitation significantly better than similar indices computed by using reanalyzed wind data prior to the 1950 s.

The changes in precipitation related to the variability of the WNPSM strength have been evaluated by comparing years of extremely weak or strong monsoon, defined respectively as the 10th and 90th percentile of the WNPDI series for its entire 1849-2014 temporal range. A total of 15 extremely strong $(1857,1866,1904$, 1920, 1923, 1924, 1929, 1937, 1940, 1941, 1961, 1981, 1985, 2001, and 2004) and 15 extremely weak (1852, 1867, 1887, 1910, 1916, 1949, 1954, 1983, 1988, 1991, 1996, 1998, 2007, 2008, and 2010) monsoons have been identified. Figure 5 shows the differences in summer precipitation for extreme phases of the monsoon related to the local precipitation average between 1901 and 2013. Values exceeding $|100 \%|$ refer to differences in precipitation between strong and weak monsoons greater than the local average, whereas negative values indicate that the amount of precipitation associated with weak WNPSM is larger than that of strong WNPSM. The largest differences, between $50 \%$ and $100 \%$ higher than the local long-term averages, are found in the northern Philippines and western Myanmar. Increases in precipitation between $25 \%$ and $50 \%$ are located in some areas of southern China, Taiwan, and eastern Indochina. Smaller but significant positive anomalies have also been found in southern Myanmar and in the southwest coast of India. On the contrary, precipitation differences drop along the Yangtze River valley and in Malaysia, northern Sumatra, Borneo, and southeastern India, where the minimum of around $-175 \%$ is reached.

In addition, a great part of the extreme monsoons were concentrated in two periods of the twentieth century. Thus, $47 \%$ of extremely strong monsoons occurred 
Strong (13) - weak (12) monsoon years 1901-2013

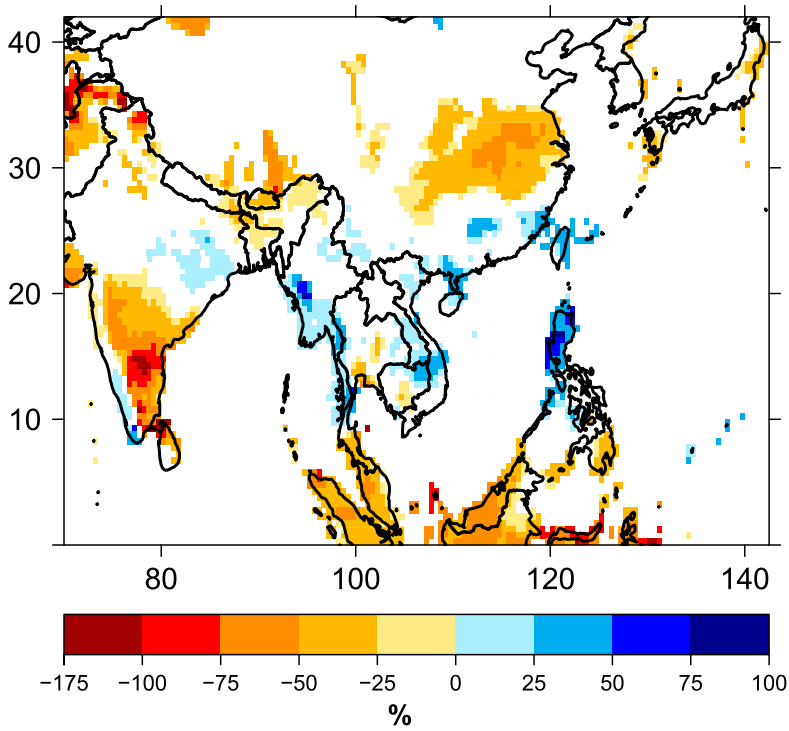

FIG. 5. Summer (JJA) composite difference of precipitation (\%; related to the JJA-average local precipitation) throughout the period 1901-2013.

in $1918-48$, whereas $53 \%$ of extremely weak monsoons developed between 1983 and 2013. Note that the two regimes are not completely the opposite as the former only includes extremely strong monsoons whereas the latter is highly variable combining a few extremely strong with many extremely weak monsoons. Figure 6 shows the summer precipitation during these two regimes of the WNPSM. Concerning the period 1918-48, precipitation was significantly higher in the $20^{\circ}-30^{\circ} \mathrm{N}$ band, and especially in Kerala, India, southern Myanmar, and the northern Philippines, where increases of up to $240 \mathrm{~mm} \mathrm{season}^{-1}$ are found (Fig. 6a). On the other hand, dryer than average conditions occurred in southern India, eastern China between the Yangtze and the Yellow Rivers, and most of Japan, reaching maximum deficits of around 100 and $300 \mathrm{~mm}$ season ${ }^{-1}$ in southern Philippines and Cambodia, respectively. The precipitation anomaly for the period 1983-2013 (Fig. 6b) shows remarkable differences with that of Fig. 6a, stressing the large decadal variability of the precipitation in the area affected by the WNPSM. The precipitation pattern in that period tended to be mostly opposite to that of the regime characterized by persistent strong monsoons, especially in India and Indonesia. This higher variability is in good agreement with the northward shift of precipitation anomalies over eastern China characteristic of this period recently reported by Zhang (2015a,b).

The former analysis shows that the WNPDI is consistently related to changes in monsoonal precipitation along the entire twentieth century, but it must be kept in mind that the WNPDI only relies on the variability of wind direction frequency; therefore, it does not explicitly include information about wind force variations and, ultimately, moisture advection. To test the suitability of the WNPDI as a measure of the changes in moisture transport related to the monsoon, we compared the 1000-300-hPa vertically integrated moisture flux and its divergence (Fig. 7a) for extremely strong or weak monsoons according to our WNPDI. Note that moisture (a) 1918-1948

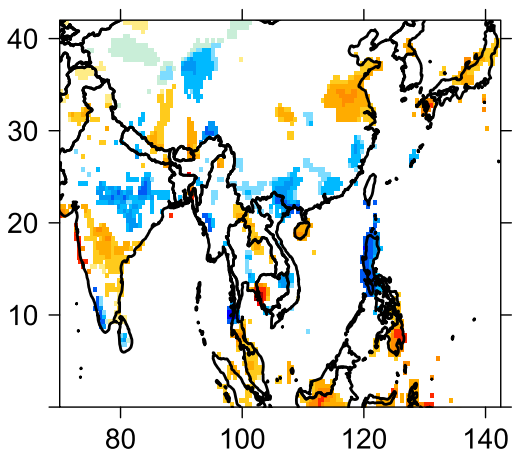

(b) 1983-2013

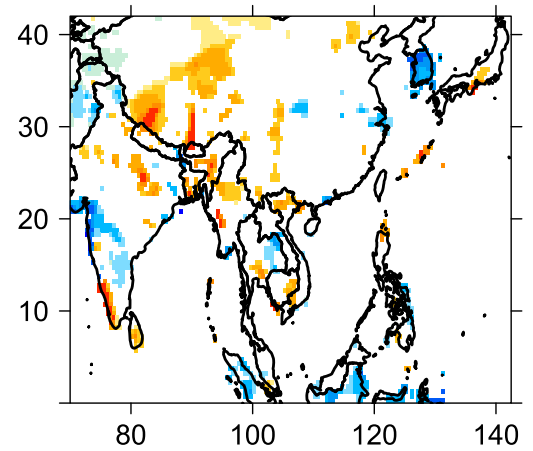

$\mathrm{mm} /$ season

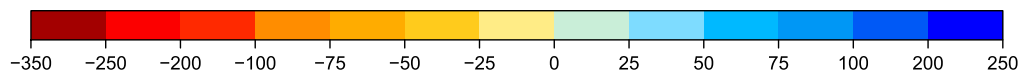

FIG. 6. Summer (JJA) precipitation anomaly for the periods (a) 1918-48 and (b) 1983-2013 regarding the period 1901-2013. Shading denotes what is significant at the $95 \%$ confidence level. 
(a) Strong (4) - weak (8) monsoon years 1981-2013

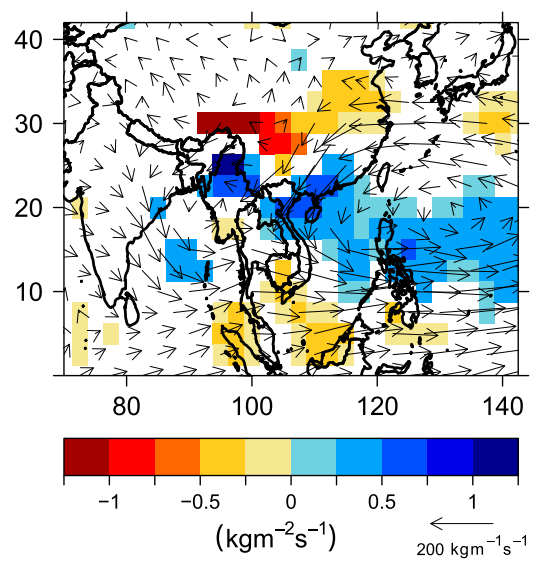

(b) Strong (4) - weak (8) monsoon years 1981-2013

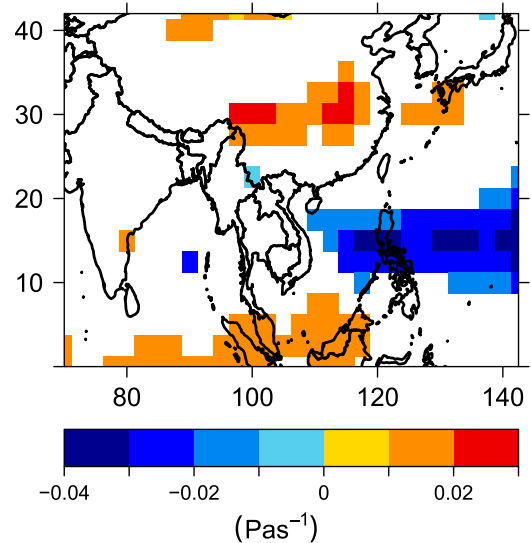

FIG. 7. Summer (JJA) composite difference of (a) moisture transport (vectors; $\mathrm{kg} \mathrm{m}^{-1} \mathrm{~s}^{-1}$ ) and its convergence (shading; $\mathrm{kg} \mathrm{m}^{-2} \mathrm{~s}^{-1}$ ) and (b) vertical velocity $\left(\mathrm{Pa} \mathrm{s}^{-1}\right)$ for the period 1981-2013 between strong and weak monsoon years. Shading denotes what is significant at the $95 \%$ confidence level.

transport has only been evaluated for extreme monsoons after 1979 because of the large uncertainty of variables such as specific humidity or vertical wind velocity previous to the satellite era over the Pacific Ocean. Figure $7 \mathrm{a}$ also shows the expected cyclonic anomaly of the moisture transport in the WNP region, which leads to a significant moisture convergence in the domain $10^{\circ}-20^{\circ} \mathrm{N}, 110^{\circ}-150^{\circ} \mathrm{E}$. This area also displays a significant increase in upward motion as a result of the enhanced convection (Fig. 7b).

\section{Relations of the WNPDI with ENSO and IOD in the twentieth century}

To explore the relationship between the WNPSM and ENSO, El Niño Modoki, or the IOD throughout the period 1900-2013, a correlation analysis between the JJA WNPDI and the seasonal EN3, EMI, and DMI was performed. To clearly separate ENSO from El Niño Modoki cases, we chose the Niño-3 index to represent ENSO in order not to include some central Pacific warmings to which the Niño-3.4 index is more sensitive (e.g., Weng et al. 2007, 2011). The values of the correlations for in-phase and negative lags (ENSO, El Niño Modoki, and IOD preceding the monsoon) are generally low (Table 1). Correlations for positive lags are moderate, but in this case they reach statistical significance in five out of six cases, with a maximum of $+0.42(p<0.05)$ between El Niño Modoki and the WNPSM during the autumn after the monsoon.

A sliding correlation analysis using a 31-yr window was carried out in order to examine the stability of the aforementioned relationships during the twentieth century. The correlation value assigned to a given year $Y$ corresponds to the Pearson correlation coefficient when considering the period from $Y-15$ to $Y+15$. In Fig. 8 we have considered lags from the previous year (season -1) until the year following the monsoon (season +1) indicated as JJA-monsoon. Note years shown in Fig. 8 correspond to the central year of the sliding correlation window. In general, this analysis reveals that the low correlation values shown in Table 1 , especially for negative lags, are mostly the result of the lack of stationarity of the ENSO-WNPSM and the El Niño Modoki-WNPSM relationships throughout the twentieth century. Figure 8a shows a profound change of the ENSO-WNPSM relationship in the 1970s. Before this decade (and especially from 1940 to 1970) the EN3WNPDI correlation was positive and mostly significant since two seasons prior to the monsoon, remaining positive for the in-phase case and up to three seasons after the monsoon. On the contrary, starting in 1970, the EN3-WNPDI correlation shows large negative and significant values since four seasons before the summer monsoon [i.e., from JJA(-1) to MAM]. For the inphase and positive lag cases, the correlation values after 1970 are still positive, but with significantly lower values than in the previous decades. The El Niño Modoki case (Fig. 8b) reveals in-phase significant positive correlation between the WNPDI and the EMI. This positive correlation is found for an entire year after the summer monsoon, and it is enhanced from the 1980s on. The autumn after the monsoon is the season when the correlation is higher and more stable during the whole study 
TABLE 1. Lag seasonal correlation between the JJA WNPDI and climatic patterns indices (Niño-3, El Niño Modoki, and the IOD) during the period 1900-2013. Significant correlations $(p<0.05)$ are shown in boldface.

\begin{tabular}{lccccr}
\hline \hline Lag & Previous winter & Previous spring & Summer & Following autumn & Following winter \\
\hline EN3 & -0.16 & -0.03 & 0.14 & $\mathbf{0 . 2 5}$ & $\mathbf{0 . 2 9}$ \\
EMI & 0 & 0.03 & $\mathbf{0 . 3 3}$ & $\mathbf{0 . 4 2}$ & $\mathbf{0 . 3 3}$ \\
DMI & -0.06 & 0.11 & 0.16 & $\mathbf{0 . 3 5}$ & -0.02 \\
\hline
\end{tabular}

period, reaching maxima up to +0.7 in the late 1990 s. In contrast, El Niño Modoki seems to be disconnected from the WNPSM for negative lags (i.e., before MAM), especially after the 1950s. Although with statistically nonsignificant values, the EMI-WNPDI correlation reversed sign for negative lags around the 1970s, similarly to EN3. Finally, Fig. 8c shows that the in-phase correlation between the IOD and the WNPSM has been quite variable (and mostly nonsignificant) during the twentieth century, except for some brief periods. Since 1980 the correlation shows moderate but yet statistically significant negative values in the autumn and winter before the monsoon. For positive lags, the most stable correlation is found for the autumn after the monsoon for the periods 1915-30 and 1948-74, exceeding values of 0.5 in the former period, suggesting that a strong WNPSM tends to be followed by positive values of the IOD. These results remain similar when performing partial correlation analysis (not shown), indicating a small linear contribution of the other factors on the correlation between the WNPSM and each of the tested indices.

As revealed by Chou et al. (2003) a simple correlation of the whole series of ENSO events is not capable of catching the subtle details of the ENSO-WNPSM relationship. They found it necessary to analyze ENSOdeveloping, ENSO-decaying, and non-ENSO years separately in order to understand the features of the interannual variability of the WNPSM properly. However, they could only perform their analysis from 1951 on. In view of the significant change in the EN3-WNPDI relationship found since 1970 shown in Fig. 8a, it makes sense to repeat their analysis with our longer series. This is not a trivial issue, as any ENSO index based on SST might have a bias before the 1950s affecting the classification of ENSO events (L'Heureux et al. 2013). As stated in section 2, we computed our EN3 and EN3.4 after removing the linear trends, but additionally, for this analysis we have included the SOI (taken from the University of East Anglia Climatic Research Unit), which is based on SLP measurements and presumably not affected by the SST bias.

To perform the classification of ENSO years, we have followed the same conventions as Chou et al. (2003):

1) ENSO-developing (decaying) years are considered as those before (after) the mature phase of an ENSO event, which is defined when the DJF value of the $\mathrm{EN} 3$ or EN3.4 is larger (smaller) than $0.9^{\circ} \mathrm{C}\left(-0.9^{\circ} \mathrm{C}\right)$ for El Niño (La Niña). A threshold of -0.9 (0.9) standard deviation units was chosen to define the mature phase of El Niño (La Niña) event in the case of the SOI. Different thresholds for this definition were tested with essentially the same results. Those years in which an event persists and those that are (a) EN3

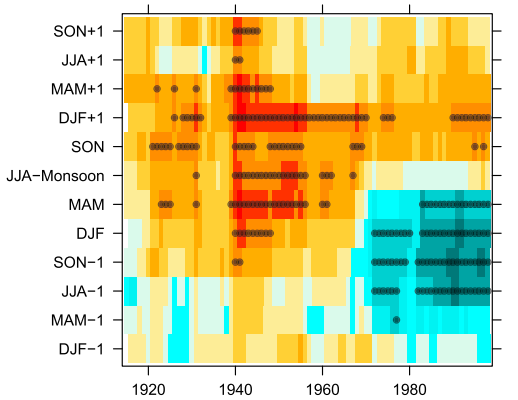

(b) EMI

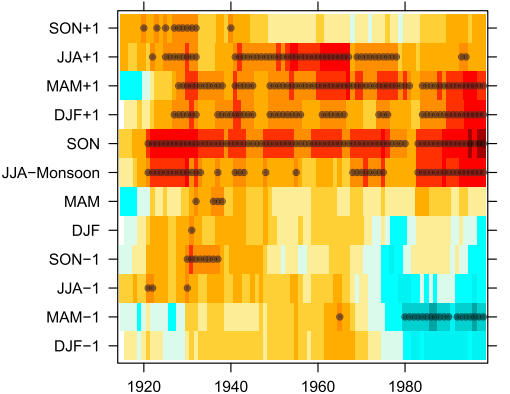

(c) DMI

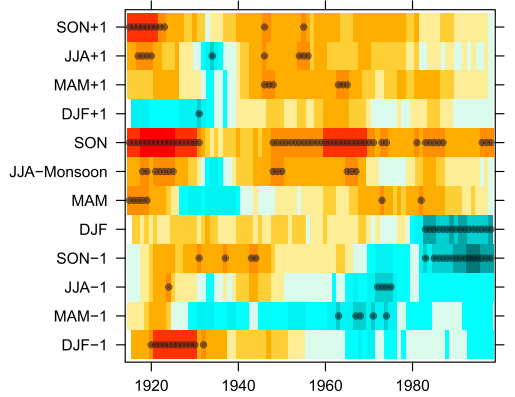

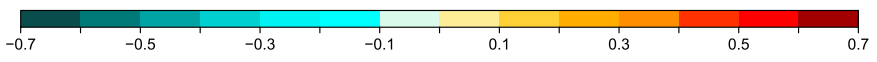

FIG. 8. Lag sliding correlation (31-yr window) of seasonal (a) EN3, (b) EMI, and (c) DMI in relation to the JJA WNPDI (indicated as JJA-monsoon). Years correspond to the central year of the sliding 31-yr window. Black points indicate significant correlations at the $90 \%$ significance level. 
(a) EN3

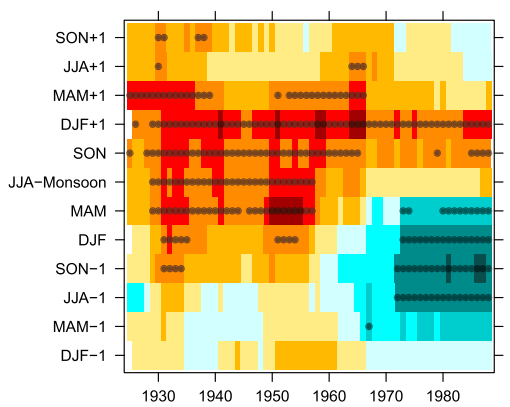

(b) EN3.4

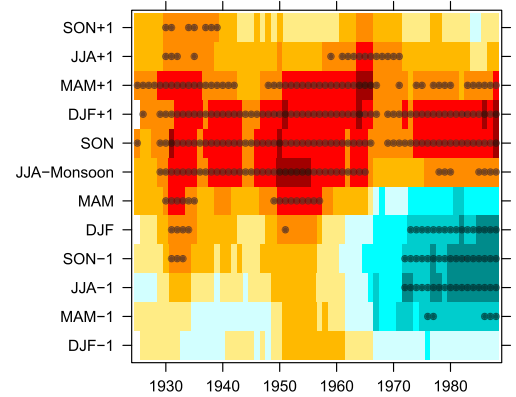

(c) Sol

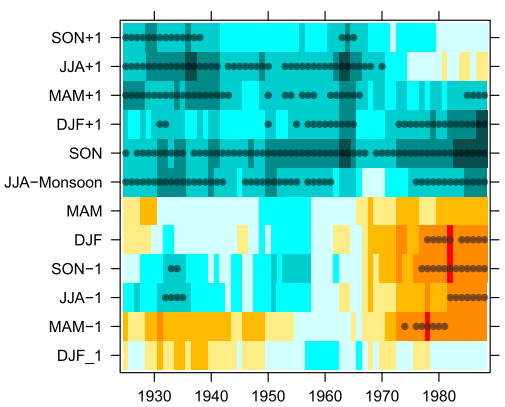

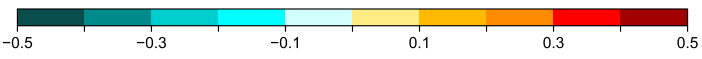

FIG. 9. Lag sliding correlation (51-yr window) of seasonal (a) EN3, (b) EN3.4 and (c) SOI in relation to the JJA WNPDI (indicated as JJA-monsoon) for the period 1900-2013. Years correspond to the central year of the sliding 51-yr window. Black points indicate significant correlations at the $90 \%$ significance level.

simultaneously developing and decaying have been excised from the analysis. Our classification based on the EN3.4 resulted in the same events as those of Chou et al. (2003) for the concurrent period (19512000).

2) The lag sliding correlation analysis was performed for the three seasonal ENSO indices (EN3, EN3.4, and SOI) with respect to the JJA WNPDI, differentiating all, ENSO-developing, ENSO-decaying, and non-ENSO years. We choose a window of $51 \mathrm{yr}$ in order to have a large enough sample of ENSO events inside the window and to ease comparison with the results of Chou et al. (2003).

3) In this analysis, a strong (weak) WNPSM is named when the WNPDI $>0($ WNPDI $<0)$ and years shown in Figs. 9 and 10 correspond to the central years of the sliding correlation window.
Figure 9 shows the result of the analysis for all monsoon years and ENSO indices. As expected, the results are consistent with the tendency of having El Niño (La Niña) conditions for several seasons after a strong (weak) WNPSM found in Fig. 8a. For negative lags we find again the change in the sign of the correlation around 1970. This indicates that the swap in the ENSOWNPSM relationship around 1970 is robust against changes in the window width or the ENSO index considered. Interestingly, when the analysis is restricted to the ENSO-developing years (Fig. 10a), the change in the correlation sign for negative lags is not observed. This result suggests that when an El Niño (La Niña) event is developing a strong (weak) WNPSM is typically preceded by negative (positive) SST anomalies over the tropical eastern Pacific up to the previous spring and followed by positive (negative) ones, and this tendency (a) ENSO developing years

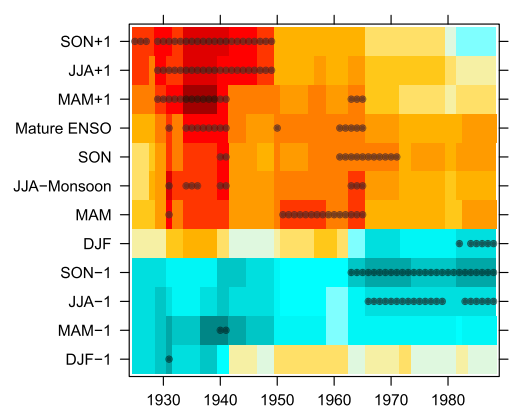

(b) ENSO decaying years

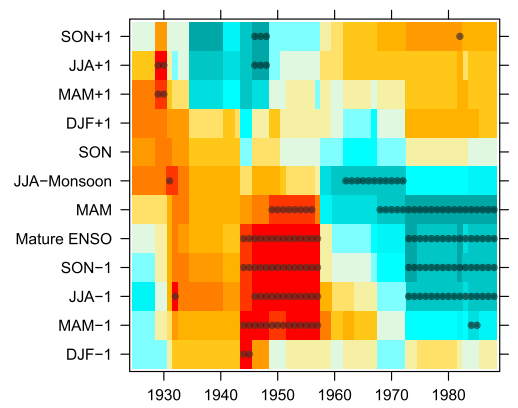

(c) Non ENSO years

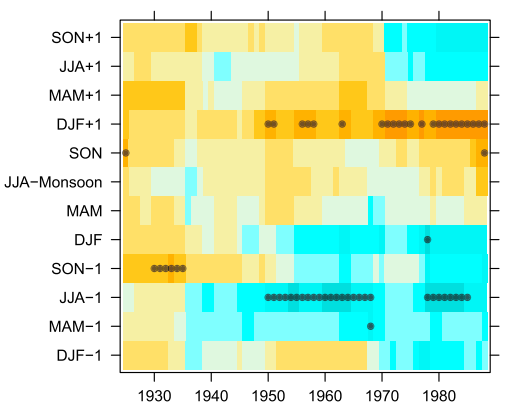

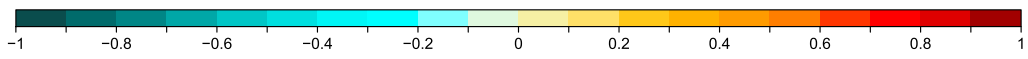

FIG. 10. Lag sliding correlation (51-yr window) of seasonal EN3 in relation to the JJA WNPDI throughout the period 1900-2013 for (a) the ENSO-developing years, (b) the ENSO-decaying years, and (c) the non-ENSO years. Summer monsoon is indicated as JJAmonsoon, whereas the peak of ENSO events is marked as "mature ENSO." Years correspond to the central year of the sliding 51-yr window. Black points indicate significant correlations at the $90 \%$ significance level. 
has been rather stable throughout the twentieth century. However, for positive lags, our result indicates that the correlation was significantly larger prior to the 1950s. The analysis for ENSO-developing years shown in Fig. 10a is in full agreement with Chou et al. (2003) for their available period (1951-2000). When the analysis is restricted to the ENSO-decaying years (Fig. 10b), we have found that a strong (weak) WNPSM tended to occur after La Niña (El Niño) for the period after the late 1950s, while for positive lags the correlation is not statistically significant. Again, this result is essentially the same found by Chou et al. (2003) for 1951-2000. Nevertheless, the longer WNPDI series evidences that prior to the late 1950s the correlation sign for negative lags reversed. In particular, between 1943 and the late $1950 \mathrm{~s}$ it was positive and as high as $+0.8(p<0.01)$ for an entire year finishing in the spring preceding the monsoon, which is generally the year in which ENSO events develop. Finally, Fig. 10c shows that the WNPSM has not been significantly connected to the central $\mathrm{Pa}$ cific equatorial SSTs in non-ENSO years.

\section{Discussion and conclusions}

In this paper we have been able to develop a new series characterizing the WNPSM based on logbook records, which has allowed us to build the longer WNPSM series currently available. Our main findings can be summarized in the following points:

1) The large correlation of our new index with the WNPMI, the index usually employed to measure the WNPSM strength, demonstrates that the intensity of the WNPSM can be quantified by using an index relying only on observations of wind direction. This is relevant because wind direction is usually the only purely instrumental meteorological observation available at open sea prior to the second half of the twentieth century. The WNPDI is also consistent with the observed monsoonal precipitation described in previous studies (e.g., Wang et al. 2001; Chang et al. 2005; Yao et al. 2008; Chou et al. 2009) throughout the entire twentieth century.

2) Although the WNPSM strength has been usually found to be highly variable at scales lower than decadal (Wang et al. 2001), the WNPDI record indicates that during the period 1918-48 the WNPSM was relatively less variable and characterized by the persistence of strong monsoons. In fact, $46 \%$ of positive extremes identified throughout the entire series occurred in the period 1918-48, including the two strongest monsoons registered in the twentieth century (1920 and 1937).
3) This regime appears to be associated with precipitation increases in the northern Philippines, southern China, and northeastern India and dryer conditions in the southern Philippines, western Cambodia, Borneo, Malaysia, Japan, central-eastern China, and southern India. Those precipitation changes might be the consequence of a stronger summer cyclonic circulation over the western North Pacific. Despite no clear consensus in the periods, some authors have also found evidence of an anomalous climate regime in the western North Pacific during the first half of the twentieth century that would be compatible with a tendency to stronger monsoons. Some studies (e.g., Minobe 1997, and references therein) describe climate shifts in the 1920s and the 1940s related to changes in the intensity and position of pressure centers, such as those of the Aleutian low and the North Pacific high (Fu et al. 1999), which would affect the monsoon strength. Fu and Fletcher (1988) detected changes in the Asian monsoonal circulation around 1900 and 1940, alternating among what they defined as "meridional," "zonal," and "neutral" monsoon regimes, respectively. In particular, wind direction in D2 would have become more easterly than average during the period 1898-1930, which would imply higher values of the WNPDI. Furthermore, the zonal monsoon regime was associated with more active monsoons as troughs located at the Bay of Bengal and the South China Sea intensified and moved northeastward, positioning over Indochina and the eastern coast of China ( Fu et al. 1999).

4) Part of the literature dealing with the WNPSM is centered in the determination of its relation with ENSO. Our results for the complete twentieth century confirm the known positive correlation between the SST in the equatorial Pacific and the WNPSM strength since the summer of the monsoon (in phase) and up to three seasons after the monsoon (positive lags). Concerning negative lags, it is commonly accepted that the lower-tropospheric anticyclonic anomaly over the western North Pacific characteristic of an El Niño event frequently persists from the El Niño mature winter to the following summer, and this is the reason why a weak WNPSM is often preceded by El Niño in the previous winter (Zhang et al. 2017). This justifies the negative correlations found by Chou et al. (2003) for negative lags that we have also found after the 1960s (Fig. 10b). However, our series indicates that this was not the case prior to the 1960s, when the correlation for negative lags of the ENSO-decaying phase was mainly positive. The causes of this change in the correlation 
sign, restricted to the ENSO-decaying phases, are still unknown, but recently, Chen et al. (2016) found that the link between ENSO and the following monsoon depends on the length of the decaying phase of El Niño. In their analysis, they proved that short-decaying El Niños result in a stronger western North Pacific anticyclone (WNPAC) and a subsequent weak WNPSM (negative correlation for negative lags). They also found that long-decaying El Niño largely inhibits the formation of the WNPAC, favoring stronger monsoon (positive correlations for negative lags). Interestingly, Chen et al. (2016) pointed out the intensification of the WNPAC response restricted to short-decaying El Niños under climate change scenarios. This could partially justify the change in the correlation limited to the ENSOdecaying phases we have found for negative lags. Along the twentieth century, the role of the shortdecaying El Niño events would become dominant, favoring the change from positive to negative correlations observed after the 1960s.

5) Recently, Weng et al. (2011) showed that in summer the WNPSM was particularly related to the pattern of El Niño Modoki measured by the EMI throughout the period 1951-2007. Our results confirm that this remains true during the entire twentieth century. Furthermore, it is interesting that the WNPDI is highly correlated with the EMI over a year after the summer monsoon, reaching the maximum in autumn. As the correlation is rather stable and high in the whole study period, the WNPDI could be considered a candidate to be a predictor of the EMI.

6) Finally, we have not found significant direct correlations with the IOD (measured by the DMI). This is not an unexpected finding because recently it has been suggested that the IOD influence on the WNPSM is indirect. Feng and Chen (2014) found that the IOD could modulate the El Niño ModokiWNPSM relationship, weakening it when a positive phase of El Niño Modoki occurs simultaneously with a positive phase of the IOD. We have tested this possibility for the entire twentieth century computing the distribution of strong and weak monsoons as a combined function of the EMI and the DMI (not shown), but we did not find a significant change in the El Niño Modoki-WNPSM relationship for opposite phases of the IOD when the entire twentieth century is considered.

Since one of the circumstances of the Asian monsoon system is its effect on densely populated areas (Wang et al. 2001), the characterization of the WNPSM is quite relevant. Nevertheless, the scarcity of data over the large oceanic areas of the Pacific has hampered the characterization of its long-term variability. Beyond updating some climatic relationships of the WNPSM with ENSO-related indices, we consider that the most important finding of the present work is the fact that the WNPSM strength can be characterized by using exclusively wind direction observations, a measurement that was routinely taken aboard ships since early times in the areas affected by the monsoon. With the historical observations currently available on ICOADS 3.0 we have developed the longest instrumental index of the WNPSM to date, doubling the length of the former longest series. According to Wheeler and García-Herrera (2008), there are still thousands of logbooks in several British archives not digitized yet, with data coverage probably since the first half of the nineteenth century over D1 and D2. The possibility of having even earlier data in these areas from Chinese or Japanese sources cannot be disregarded. The relevance of the WNPSM for the global climate (e.g., Wang et al. 2001; Lee et al. 2014; Choi et al. 2016) would largely justify the time and economic cost of the finding and digitization of these sources in order to better characterize the time evolution of the WNPSM.

Acknowledgments. This research was funded by the Spanish Ministry of Economy and Competitiveness through the project CGL2013-44530-P and the Grant BES-2014-069733. Comments from three anonymous reviewers helped to improve the original manuscript. GPCC precipitation data (version 7), Twentieth Century Reanalysis version v2c data, 1948-2013 NCEP-NCAR reanalysis version 2 data, ICOADS 3.0 data, and COBESST release 2 data are provided by NOAA/OAR/ESRL PSD, Boulder, Colorado, from their website (http://www. esrl.noaa.gov/psd/). ERA-20C data are provided by the ECMWF from their website (http://www.ecmwf.int/en/ research/climate-reanalysis).

\section{REFERENCES}

Ashok, K., S. K. Behera, S. A. Rao, H. Weng, and T. Yamagata, 2007: El Niño Modoki and its possible teleconnection. J. Geophys. Res., 112, C11007, https://doi.org/10.1029/ 2006JC003798.

Barriopedro, D., D. Gallego, M. C. Álvarez-Castro, R. GarcíaHerrera, D. Wheeler, C. Peña-Ortiz, and S. M. Barbosa, 2014: Witnessing North Atlantic westerlies variability from ships' logbooks (1685-2008). Climate Dyn., 43, 939-955, https://doi.org/10.1007/s00382-013-1957-8.

Chang, C.-P., Z. Wang, J. McBride, and C.-H. Liu, 2005: Annual cycle of Southeast Asia-Maritime Continent rainfall and the asymmetric monsoon transition. J. Climate, 18, 287-301, https://doi.org/10.1175/JCLI-3257.1. 
Chen, W., J.-Y. Lee, K.-J. Ha, K.-S. Yun, and R. Lu, 2016: Intensification of the western North Pacific anticyclone response to the short decaying El Niño event due to greenhouse warming. J. Climate, 29, 3607-3627, https://doi.org/10.1175/ JCLI-D-15-0195.1.

Choi, K.-S., Y. Cha, H.-D. Kim, and S.-D. Kang, 2016: Possible influence of western North Pacific monsoon on TC activity in mid-latitudes of East Asia. Climate Dyn., 46, 1-13, https:// doi.org/10.1007/s00382-015-2562-9.

Chou, C., J.-Y. Tu, and J.-Y. Yu, 2003: Interannual variability of the western North Pacific summer monsoon: Differences between ENSO and non-ENSO years. J. Climate, 16, 2275-2287, https://doi.org/10.1175/2761.1.

_ L L.-F. Huang, L. Tseng, J.-Y. Tu, and P.-H. Tan, 2009: Annual cycle of rainfall in the western North Pacific and East Asian sector. J. Climate, 22, 2073-2094, https://doi.org/10.1175/ 2008JCLI2538.1.

Compo, G. P., and Coauthors, 2011: The Twentieth Century Reanalysis Project. Quart. J. Roy. Meteor. Soc., 137, 1-28, https:// doi.org/10.1002/qj.776.

Fan, F., M. E. Mann, and C. M. Ammann, 2009: Understanding changes in the Asian summer monsoon over the past millennium: Insights from a long-term coupled model simulation. J. Climate, 22, 1736-1748, https://doi.org/10.1175/ 2008JCLI2336.1.

Feng, J., and W. Chen, 2014: Influence of the IOD on the relationship between El Niño Modoki and the East Asianwestern North Pacific summer monsoon. Int. J. Climatol., 34, 1729-1736, https://doi.org/10.1002/joc.3790.

Freeman, E., and Coauthors, 2017: ICOADS Release 3.0: A major update to the historical marine climate record. Int. J. Climatol., 37, 2211-2232, https://doi.org/10.1002/joc.4775.

$\mathrm{Fu}, \mathrm{C}$., and J. Fletcher, 1988: Large signals of climatic variation over the ocean in the Asian monsoon region. Adv. Atmos. Sci., 5, 389-404, https://doi.org/10.1007/BF02656786.

— , H. F. Díaz, D. Dong, and J. O. Fletcher, 1999: Changes in atmospheric circulation over Northern Hemisphere oceans associated with the rapid warming of the 1920s. Int. J. Climatol., 19, 581-606, https://doi.org/10.1002/(SICI)1097-0088(199905)19: 6<581::AID-JOC396>3.0.CO;2-P.

Gallego, D., R. García-Herrera, N. Calvo, and P. Ribera, 2007: A new meteorological record for Cádiz (Spain) 1806-1852: Implications for climatic reconstructions. J. Geophys. Res., 112, D12108, https://doi.org/10.1029/2007JD008517.

_ , P. Ordóñez, P. Ribera, C. Peña-Ortiz, and R. García-Herrera, 2015: An instrumental index of the West African monsoon back to the nineteenth century. Quart. J. Roy. Meteor. Soc., 141, 3166-3176, https://doi.org/10.1002/qj.2601.

García-Herrera, R., C. Wilkinson, F. B. Koek, M. R. Prieto, N. Calvo, and E. Hernández, 2005: Description and general background to ships' logbooks as a source of climatic data. Climatic Change, 73, 13-36, https://doi.org/10.1007/ s10584-005-6954-4.

Hirahara, S., M. Ishii, and Y. Fukuda, 2014: Centennial-scale sea surface temperature analysis and its uncertainty. J. Climate, 27, 57-75, https://doi.org/10.1175/JCLI-D-12-00837.1.

Kalnay, E., and Coauthors, 1996: The NCEP/NCAR 40-Year Reanalysis Project. Bull. Amer. Meteor. Soc., 77, 437-471, https:// doi.org/10.1175/1520-0477(1996)077<0437:TNYRP>2.0.CO;2.

Küttel, M., and Coauthors, 2010: The importance of ship log data: Reconstructing North Atlantic, European and Mediterranean sea level pressure fields back to 1750 . Climate Dyn., 34, 1115-1128, https://doi.org/10.1007/s00382-009-0577-9.
Kwon, M., J.-G. Jhun, B. Wang, S.-I. An, and J.-S. Kug, 2005: Decadal change in relationship between East Asian and WNP summer monsoons. Geophys. Res. Lett., 32, L16709, https:// doi.org/10.1029/2005GL023026.

Lee, E.-J., K.-J. Ha, and J.-G. Jhun, 2014: Interdecadal changes in interannual variability of the global monsoon precipitation and interrelationships among its subcomponents. Climate Dyn., 42, 2585-2601, https://doi.org/10.1007/s00382-013-1762-4.

L'Heureux, M. L., D. C. Collins, and Z.-Z. Hu, 2013: Linear trends in sea surface temperature of the tropical Pacific Ocean and implications for the El Niño-Southern Oscillation. Climate Dyn., 40, 1223-1236, https://doi.org/10.1007/s00382-012-1331-2.

Minobe, S., 1997: A 50-70 year climatic oscillation over the North Pacific and North America. Geophys. Res. Lett., 24, 683-686, https://doi.org/10.1029/97GL00504.

Murakami, T., and J. Matsumoto, 1994: Summer monsoon over the Asian continent and western North Pacific. J. Meteor. Soc. Japan, 72, 719-745, https://doi.org/10.2151/jmsj1965.72.5_719.

Ordóñez, P., D. Gallego, P. Ribera, C. Peña-Ortiz, and R. GarcíaHerrera, 2016: Tracking the Indian summer monsoon onset back to the preinstrument period. J. Climate, 29, 8115-8127, https://doi.org/10.1175/JCLI-D-15-0788.1.

Parthasarathy, B., A. A. Munot, and D. R. Kothawale, 1994: All-India monthly and seasonal rainfall series: 1871-1993. Theor. Appl. Climatol., 49, 217-224, https://doi.org/10.1007/BF00867461.

Poli, P., and Coauthors, 2016: ERA-20C: An atmospheric reanalysis of the twentieth century. J. Climate, 29, 4083-4097, https://doi.org/10.1175/JCLI-D-15-0556.1.

Prieto, M. R., D. Gallego, R. García-Herrera, and N. Calvo, 2005: Deriving wind force terms from nautical reports through content analysis. The Spanish and French cases. Climatic Change, 73, 37-55, https://doi.org/10.1007/s10584-005-6956-2.

Saji, N. H., B. N. Goswami, P. N. Vinayachandran, and T. Yamagata, 1999: A dipole mode in the tropical Indian Ocean. Nature, 401, 360-363.

Schneider, U., A. Becker, P. Finger, A. Meyer-Christoffer, M. Ziese, and B. Rudolf, 2014: GPCC's new land surface precipitation climatology based on quality-controlled in situ data and its role in quantifying the global water cycle. Theor. Appl. Climatol., 115, 15-40, https://doi.org/10.1007/s00704-013-0860-x.

Tanaka, M., 1997: Interannual and interdecadal variations of the western North Pacific monsoon and baiu rainfall and their relationship to the ENSO cycles. J. Meteor. Soc. Japan, 75, 1109-1123, https://doi.org/10.2151/jmsj1965.75.6_1109.

Tao, S., and L. Chen, 1987: A review of recent research on the East Asian summer monsoon in China. Monsoon Meteorology, C.-P. Chang and T. N. Krishnamurti, Eds., Oxford University Press, 60-92.

Trenberth, K. E., and C. J. Guillemot, 1995: Evaluation of the global atmospheric moisture budget as seen from analyses. J. Climate, 8, 2255-2272, https://doi.org/10.1175/1520-0442(1995)008<2255: EOTGAM $>2.0 . C O ; 2$.

Wang, B., and Z. Fan, 1999: Choice of South Asian summer monsoon indices. Bull. Amer. Meteor. Soc., 80, 629-638, https://doi.org/ 10.1175/1520-0477(1999)080<0629:COSASM > 2.0.CO;2.

— and LinHo, 2002: Rainy season of the Asian-Pacific summer monsoon. J. Climate, 15, 386-398, https://doi.org/10.1175/ 1520-0442(2002)015<0386:RSOTAP $>2.0$.CO;2.

_ - R. Wu, and K.-M. Lau, 2001: Interannual variability of the Asian summer monsoon: Contrasts between the Indian and the western North Pacific-East Asian monsoons. J. Climate, 14, 4073-4090, https://doi.org/10.1175/1520-0442(2001)014<4073: IVOTAS $>2.0 . \mathrm{CO} ; 2$. 
Wang, X., and C. Wang, 2014: Different impacts of various El Niño events on the Indian Ocean dipole. Climate Dyn., 42, 9911005, https://doi.org/10.1007/s00382-013-1711-2.

Weng, H., K. Ashok, S. K. Behera, S. A. Rao, and T. Yamagata, 2007: Impacts of recent El Niño Modoki on dry/wet conditions in the Pacific rim during boreal summer. Climate Dyn., 29, 113-129, https://doi.org/10.1007/s00382-007-0234-0.

, G. Wu, Y. Liu, S. K. Behera, and T. Yamagata, 2011: Anomalous summer climate in China influenced by the tropical Indo-Pacific Oceans. Climate Dyn., 36, 769-782, https:// doi.org/10.1007/s00382-009-0658-9.

Wheeler, D., and R. García-Herrera, 2008: Ships' logbooks in climatological research. Ann. N. Y. Acad. Sci., 1146, 1-15, https:// doi.org/10.1196/annals.1446.006.

,-- C. W. Wilkinson, and C. Ward, 2010: Atmospheric circulation and storminess derived from Royal Navy logbooks: 1685 to 1750 . Climatic Change, 101, 257-280, https://doi.org/ 10.1007/s10584-009-9732-x.

Yao, C., S. Yang, W. Qian, Z. Lin, and M. Wen, 2008: Regional summer precipitation events in Asia and their changes in the past decades. J. Geophys. Res., 113, D17107, https://doi.org/ 10.1029/2007JD009603.
Yim, S.-Y., S.-W. Yeh, R. Wu, and J.-G. Jhun, 2008: The influence of ENSO on decadal variations in the relationship between the East Asian and western North Pacific summer monsoons. J. Climate, 21, 3165-3179, https://doi.org/10.1175/2007JCLI1948.1.

Zhang, R.-H., 2015a: Changes in East Asian summer monsoon and summer rainfall over eastern China during recent decades. Sci. Bull., 60, 1222-1224, https://doi.org/10.1007/s11434-015-0824-x. , 2015b: Natural and human-induced changes in summer climate over the East Asian monsoon region in the last half century: A review. Adv. Climate Change Res., 6, 131-140, https://doi.org/10.1016/j.accre.2015.09.009.

_, Q.-Y. Min, and J.-Z. Su, 2017: Impact of El Niño on atmospheric circulations over East Asia and rainfall in China: Role of the anomalous western North Pacific anticyclone. Sci. China, 60D, 1124-1132, https://doi.org/10.1007/s11430-016-9026-x.

Zhang, W., and M. Luo, 2016: A possible linkage of the western North Pacific summer monsoon with the North Pacific Gyre Oscillation. Atmos. Sci. Lett., 17, 437-445, https://doi.org/10.1002/asl.676.

—, Y. Wang, F.-F. Jin, M. F. Stuecker, and A. G. Turner, 2015: Impact of different El Niño types on the El Niño/IOD relationship. Geophys. Res. Lett., 42, 8570-8576, https://doi.org/ 10.1002/2015GL065703. 